\title{
Retraction Note to: Ready Mealy, Moore \& Markov Mathematical Modeling Machines for Big Data
}

\author{
Hafiz Tahir Furqan, Ahmad Abdul Wahab, Sultan Sadiq,
} and Pir Amad Ali Shah

\section{Retraction Note to: \\ Chapter "Ready Mealy, Moore \& Markov Mathematical Modeling Machines for Big Data" in: J. Ferreira and M. Alam (Eds.): Future Intelligent Vehicular Technologies, LNICST 185, https://doi.org/10.1007/978-3-319-51207-5_21}

The editors have retracted this chapter by Furqan et al. [1] because of overlap with a preprint by Cholewa et al. that was previously posted on arXiv [2]. All authors agree to this retraction.

References:

[1] Furqan H.T., Wahab A.A., Sadiq S., Ali Shah P.A. (2017). Ready Mealy, Moore \& Markov Mathematical Modeling Machines for Big Data. In: Ferreira J., Alam M. (eds.) Future Intelligent Vehicular Technologies. Future 5V 2016. Lecture Notes of the Institute for Computer Sciences, Social Informatics and Telecommunications Engineering, vol 185. Springer, Cham

[2] Michal Cholewa, Piotr Gawron, Przemyslaw Glomb, Dariusz Kurzyk. Quantum Hidden Markov Models based on Transition Operation Matrices arXiv:1503.08760v1 